DOI: $10.20472 / \mathrm{IAC} .2017 .33 .033$

\author{
MINJI KIM \\ Inje University, Korea, Republic of \\ EUITAY JUNG \\ Inje University, Korea, Republic of
}

\title{
ANALYSIS OF CONDITIONS AND PROBLEMS OF THE OUTDOOR ADVERTISING IN GIMHAE-SI, SOUTH KOREA
}

\begin{abstract}
:
The outdoor advertisement is an essential way for companies or stores to deliver diverse information to users. Regarding the outdoor advertisement, for the harmony with buildings or street environment, there are several elements to be considered such as size, color, shape, type, attachment method, design, number of advertisement board. They should be closely managed as these elements have huge influence on the visual quality of street environment. However, in Korea, local governments is making the outdoor advertisement guidelines and then practicing the guidelines to improve the visual quality of street environment, but has not been communicated smoothly so far. Thus the current outdoor advertisement in Korea were jumbled up with the surrounding buildings, making the order of the whole street unharmonious. Thus, it is the moment to have a personal view for the harmony between the clean urban image, outdoor advertisement, and surrounding environment.

This study aims to analyze the actual status of outdoor advertising and also to draw problems focusing on the domestic/foreign case study and the representative commercial districts of Gimhae-si such as Naeoe-dong and Eobang-dong.
\end{abstract}

\section{Keywords:}

Outdoor Advertisement, Urban Design, Street Environment 